\title{
Cost-Utility Analysis of a Cardiac Telerehabilitation Program: The Teledialog Project
}

Kristian Kidholm, PhD, ${ }^{1}$ Maja Kjœr Rasmussen, $\mathrm{MS}^{1}$ Jan Jesper Andreasen, $P h D_{1}^{2,3}$ John Hansen, $P h D_{1}^{4}$ Gitte Nielsen, $P h D^{5}$ Helle Spindler, $P h D^{6}$

and Birthe Dinesen, $P h D^{7}$

${ }^{1}$ Center for Innovative Medical Technology, Odense University Hospital, Odense, Denmark.

${ }^{2}$ Department of Cardiothoracic Surgery, Aalborg University Hospital, Aalborg, Denmark.

${ }^{3}$ Department of Clinical Medicine, Aalborg University, Aalborg, Denmark.

${ }^{4}$ Laboratory for Cardio-Technology, Medical Informatics Group, Department of Health Science and Technology, Faculty of Medicine, Aalborg University, Aalborg, Denmark.

${ }^{5}$ Department of Cardiology, Vendsyssel Hospital, Hjoerring, Denmark.

${ }^{6}$ Department of Psychology and Behavioral Sciences, Aarhus Graduate School of Business and Social Sciences, Aarhus University, Aarhus, Denmark.

${ }^{7}$ Telehealth and Telerehabilitation, Laboratory of Assistive Technologies, SMI ${ }^{\circledR}$, Department of Health Science and Technology, Faculty of Medicine, Aalborg University, Aalborg, Denmark.

This study has been registered at ClinicalTrials.gov with clinical trial registration number NCT01752192.

\section{Abstract}

Background: Cardiac rehabilitation can reduce mortality of patients with cardiovascular disease, but a frequently low participation rate in rehabilitation programs has been found globally. The objective of the Teledialog study was to assess the cost-utility (CU) of a cardiac telerehabilitation (CTR) program. The aim of the intervention was to increase the patients' participation in the CTR program. At discharge, an individualized 3-month rehabilitation plan was formulated for each patient. At home, the patients measured their own blood pressure, pulse, weight, and steps taken for 3 months. Materials and Methods: The analysis was carried out to- gether with a randomized controlled trial with 151 patients during 2012-2014. Costs of the intervention were estimated with a health sector perspective following international guidelines for CU. Quality of life was assessed using the 36Item Short Form Health Survey. Results: The rehabilitation activities were approximately the same in the two groups, but the number of contacts with the physiotherapist was higher among the intervention group. The mean total cost per patient was $€ 1,700$ higher in the intervention group. The qualityadjusted life-years (QALYS) gain was higher in the intervention group, but the difference was not statistically significant. The incremental CU ratio was more than $€ 400,000$ per $Q A L Y$ gained. Conclusions: Even though the rehabilitation activities increased, the program does not appear to be cost-effective. The intervention itself was not costly (less than €500), and increasing the number of patients may show reduced costs of the devices and make the CTR more cost-effective. Telerehabilitation can increase participation, but the intervention, in its current form, does not appear to be cost-effective.

Key words: cost-utility, heart patients, telerehabilitation, randomized study, economic evaluation

\section{Introduction}

$\longrightarrow$ ardiovascular diseases (CVD) is the cause of 30\% of all deaths in 2010. ${ }^{1}$ Cardiac rehabilitation (CR) has documented a $20 \%$ reduction in all-cause mortality and a $27 \%$ reduction in cardiac mortality in systematic reviews. ${ }^{2,3}$ A CR program is defined as a secondary preventive program that includes interventions such as exercise and patient education on risk factors in order to achieve and maintain a healthy lifestyle. ${ }^{4}$ Globally, low participation rates for patients in CR programs have been reported. ${ }^{5}$ Cardiac telerehabilitation (CTR) is defined as CR using information and communication technology. CTR appears to be an effective strategy to increase both patients' attendance in CR and longterm adherence to recommendations, as well as being in

(c) Kristian Kidholm, et al., 2015; Published by Mary Ann Liebert, Inc. This Open Access article is distributed under the terms of the Creative Commons Attribution Noncommercial License (http://creativecommons.org/licenses/by-nc/4.0/) which permits any noncommercial use, distribution, and reproduction in any medium, provided the original author(s) and the source are credited. 


\section{KIDHOLM ET AL.}

particular a promising new tool to include patients who are not able to attend such a program for various reasons. ${ }^{6,7}$ However, there is a lack of multidisciplinary evaluations of CTR programs, including health economic studies. ${ }^{6}$

This study conducted a cost-utility (CU) analysis (CUA) of the Teledialog research project. The aim of the project was to develop and test an individualized CTR program designed to increase participation in rehabilitation, improve patient quality of life, reduce the number of admissions, and reduce the need for acute care. As part of the Teledialog project, a CTR program was developed and tested in a randomized controlled trial of cardiac patients diagnosed with artery sclerosis, coronary artery bypass surgery, valve surgery, and heart failure.

\section{Materials and Methods}

\section{THE INTERVENTION}

A CTR program was developed and tested in 2012-2014 in a randomized controlled trial $(n=151)$. Two hospitals, four municipal healthcare centers, and a call center took part in the program. On being discharged from hospital, the cardiac patients were enrolled by a project nurse, who included the patients based on various inclusion and exclusion criteria (Table 1).

Table 1. Inclusion and Exclusion Criteria
in the Teledialog Project
CRITERIA

IT, information technology.
The project nurse performed an interview with each patient and identified the patient's need for rehabilitation and the place where rehabilitation would be carried out (hospital, healthcare center, or call center). The important part of the CTR was to design an individual rehabilitation based on the patient's needs.

The patient was registered as a user in the information technology platforms and was equipped with a tablet computer giving him or her Web access to his or her own personal health record and measurements. The patient received training in the use of the different devices and the digital rehabilitation plan, and a doctor prescribed how often the patient needed to measure blood pressure, pulse, and weight, most often twice a week, whereas steps were measured every day. The data were transmitted via a secure transmission line. Patients, relatives, and healthcare professionals from the hospital and healthcare centers were able to communicate and share data from the personal health record. In addition, patients and relatives had access to Activeheart.dk (a digital toolbox with information on rehabilitation topics, activities, and videos showing patients describing their experiences of being a heart patient and appropriate exercises for after surgery).

After 2 weeks in the program, each patient was visited by a project assistant in order to make sure that the patient and relative were confident in using the technology. Healthcare professionals monitored the measured values every week, contacted the patients if the values were abnormal, and discussed rehabilitation activities with the patient. The telerehabilitation program lasted for 3 months. Table 2 gives further description of the equipment.

The control group followed a traditional rehabilitation program at the hospital or healthcare center based on CR guidelines. Aalborg University was responsible for the delivery, installation, and removal of the equipment for the patients in the intervention group.

\section{RANDOMIZATION}

When the patient had signed the informed consent form, a project nurse performed the randomization. Randomization into groups was done using an automatically generated list for each block with an equal number of intervention and control numbers in random order, so as to ensure an even distribution in each group in varying sizes (10,20, and 14). In total, 151 cardiac patients were enrolled.

\section{OUTCOME MEASUREMENT}

Quality of life was assessed using the 36-Item Short Form Health Survey (SF-36). To estimate the changes in the number 


\section{COST-UTILITY ANALYSIS OF CARDIAC TELEREHABILITATION}

Table 2. Description of the Equipment

EQUIPMENT

USAGE

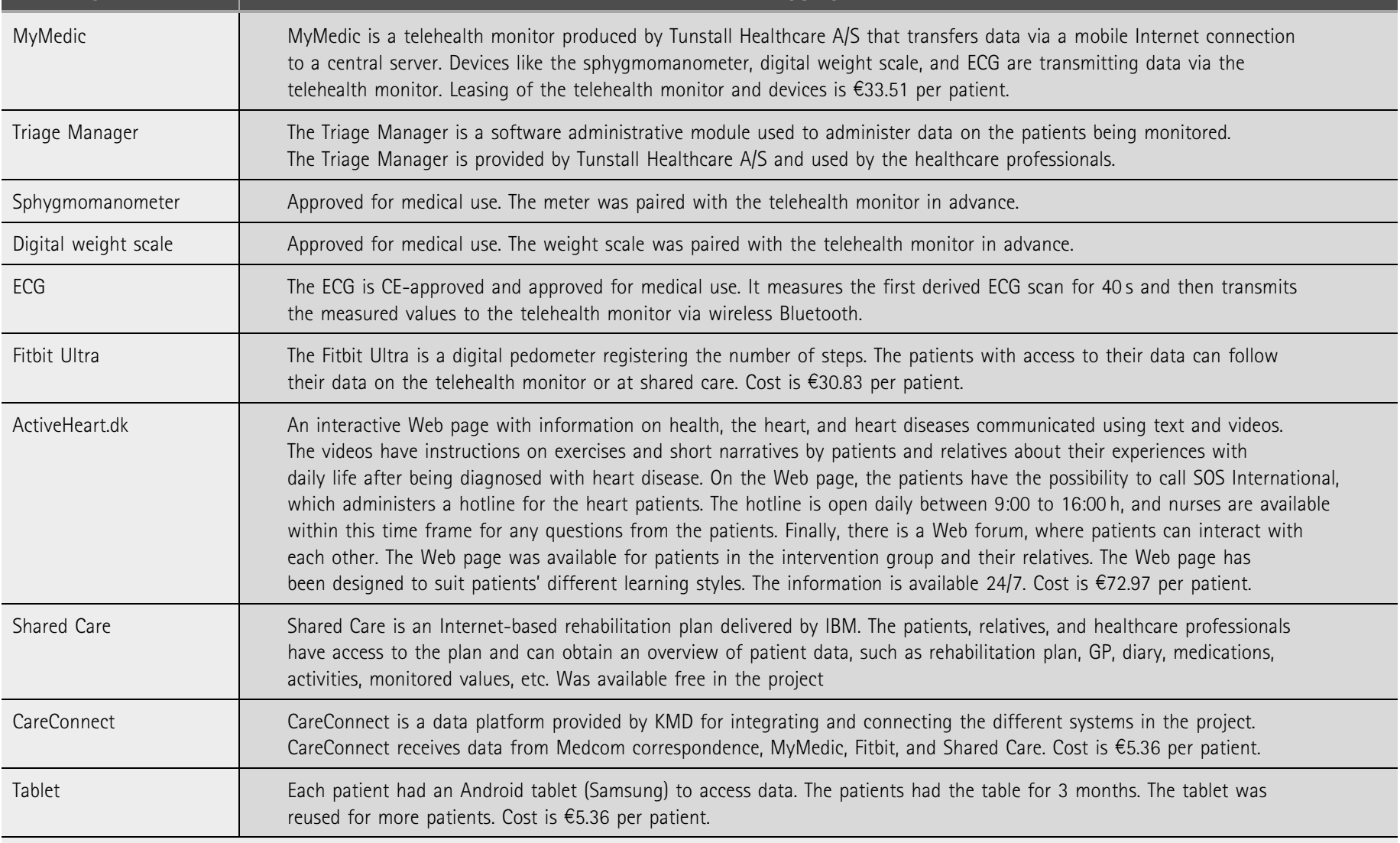

ECG, electrocardiograph; GP, general practitioner.

of quality-adjusted life-years (QALYs), the patients' responses to the SF-36 have been transformed using the Brazier algorithm and the SF-6D methodology. ${ }^{8}$ This routine applies a nonparametric model to estimate SF-6D health state utility values using Bayesian methods. ${ }^{9}$ The SF-6D comes with a set of preference weights obtained from a sample of the British population using the standard gamble method. ${ }^{9}$ Patients who complete the questionnaires may be uniquely classified in terms of QALY values according to the SF-6D. ${ }^{8}$

\section{COST MEASUREMENTS}

The CUA is based on a health sector perspective. The economic evaluation follows international guidelines for conducting a CUA of a randomized controlled trial. ${ }^{10}$ All prices and unit costs are in euros, calculated from Danish kroner (DKK) at the exchange rate of $€ 100=$ DKK $746 .{ }^{11}$

Only direct healthcare costs are considered (i.e., costs related to the intervention [equipment, training by professionals] and to the use of healthcare [hospital admissions, ambulatory contacts, general practitioner contacts, emergency physician contacts, and other primary services]). Data on costs of the intervention, including prices of equipment used in the intervention, were obtained from companies and from worktime records of the clinical staff. Data on use of healthcare were collected for each patient from the National Patient Register and is measured in the years 2013-2014. Estimates of prices of use of inpatient and outpatient hospital care for each patient were derived from the National Patient Register and based on Diagnose Related Groups from the Danish reimbursement system.

\section{ANALYSIS OF DATA}

The statistical analysis of data is based on the intentionto-treat method. Data from the SF-36 were entered into EpiData (version 1.4.1) and transferred using EpiData Manager (version 1.3.2.1.) to a statistical package ( $R$ version. 3.1.2) for analysis. The intervention and control groups were compared using descriptive statistics and tested by $t$ test. 


\section{KIDHOLM ET AL.}

These tests are applied to approximately normal data as baseline characteristics and QALY measures. Data on use of resources and costs are skewed and do not follow a normal distribution. This means that the groups are compared by their means but tested using the nonparametric MannWhitney U test for differences. Statistical significance was defined at a 5\% significance level. The results are presented with means for all variables included in the economic evaluation.

\section{ETHICAL PERMISSION}

The project was approved by the Danish Ethical Committee (number 20120051). The ethical principles for medical research involving human subjects, described in the Helsinki Declaration and the Act on Processing of Personal Data, were followed.

\section{Results}

Altogether, 369 patients were screened (Fig. 1), and 151 patients were eligible and randomized. Baseline data were collected for 141 of the eligible patients (72 for the intervention group and 69 for the control group). Attrition was acceptable, as $88 \%$ of the patients completed the 6-month follow-up assessment (90\% from the intervention group and 83\% from the control group), and 84\% completed the 12-month follow-up (89\% from the intervention group and $80 \%$ from the control group).

Table 3 shows the patients' characteristics at baseline. Tests of association conducted for each variable across randomization group confirmed that baseline characteristics did not differ statistically.

\section{ESTIMATED COSTS}

Data about the use of resources to carry out the intervention and the use of rehabilitation and healthcare services in the intervention and control groups is shown in Table 4.

With regard to rehabilitation services, we found that those in the intervention group used the physiotherapist an average of 5 times and the team training an average 2.2 times; among the control group the corresponding figures were 2.9 and 3.4, respectively. However, these differences are statistically insignificant. Generally, the use of healthcare services is higher in the intervention group except for contacts to emergency doctors. However, the average number of contacts in the control group may be severely skewed due to an outlier in the control group who had 27 contacts, and the nonparametric test confirms that the difference is not significant.

The estimated mean costs per patient are presented in Table 5. The intervention in itself costs $€ 392$ per patient, including both the costs of devices and staff resources. In the intervention group, the overall costs are for rehabilitation services about $€ 100$ higher and for healthcare services about $€ 1,200$ higher, but neither difference is statistically significant. Nevertheless, the cost of reimbursed transportation to rehabilitation is significantly higher in the control group.

The total costs of healthcare utilization are $€ 1,200$ higher on average in the intervention group, although not statistically significant. This is due mainly to the higher number of admissions. However, the total average cost per patient in the intervention group is significantly higher $(€ 5,709)$ compared with the control group $(€ 4,045)$, although this difference may be due to the added cost of the intervention.

\section{ESTIMATED QALYS}

The reported values in Table 6 are QALYs derived from the respondents' answers to SF-36 during the project. With an increase of 0.089 QALY in the intervention group and 0.085 QALY in the control group during the first 12 months, the difference is not significant. However, the estimated QALY show a significant increase over time in both groups.

\section{ESTIMATED INCREMENTAL CU RATIO}

The incremental cost-effectiveness ratio (ICER) is calculated according to the following formula:

$$
I C E R=\frac{C_{\mathrm{I}}-C_{\mathrm{C}}}{Q A L Y_{\mathrm{I}}-Q A L Y_{\mathrm{C}}}
$$

where $C_{i}(i=I, C)$ is equal to the mean costs per patient in the two groups, where I represents the intervention group and C represents the control group. The denominator consists of the change in QALY from baseline (0 month) to the 12-month follow-up for both intervention and control groups. Based on the estimates in Tables 5 and 6, ICER can be estimated to $€ 518,280$ per QALY gained. Thus, the estimated total costs of investing in Teledialog are €518,280 per gained QALY.

Uncertainty of the estimated ICER was evaluated with probabilistic sensitivity analysis using a 5,000 bootstrap resample with a 95\% bias-adjusted confidence interval (CI). The results of the resample are illustrated in the cost-effectiveness plane in Figure 2. Based on the resample, the mean costs per patient in the intervention and control groups were estimated to be $€ 5,724$ (CI: 3,$709 ; 953$ ) and $€ 4,057$ (CI: 2,445; 689), respectively, and the mean QALY gain to be 0.089 (CI: 0.05; 0.13 ) and 0.085 (CI: 0.05; 0.12), whereas the mean ICER was $€ 483,608$.

Several sensitivity analyses were carried out to examine the robustness of the results. First, patients with very high costs (costs of more than $€ 33,500$ ) were excluded (4 patients). This 


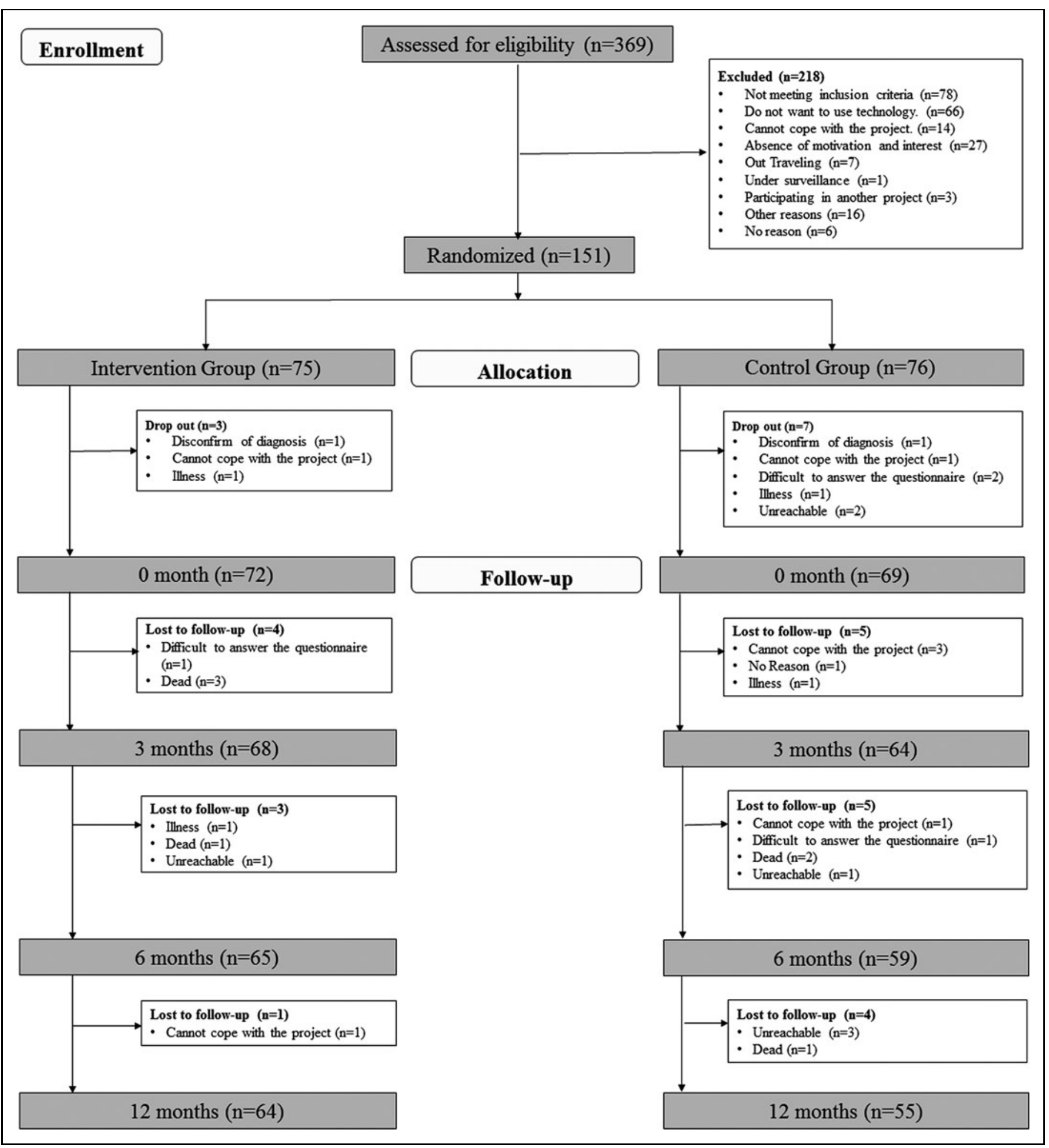

Fig. 1. Overview of cardiac patients included in the Teledialog project. 


\section{KIDHOLM ET AL.}

\section{Table 3. Basic Characteristics of the Telerehabilitation and Control Groups}

\section{VARIABLE}

TELEREHABILITATION GROUP $(N=72)$

CONTROL GROUP $(N=69)$

$P$ VALUE

Age (years) by gender

\begin{tabular}{|c|c|c|c|}
\hline Men & $63.890 \pm 11.650(31-88)[57-72](n=56)$ & $61.270 \pm 11.780(39-83)[53-70](n=55)$ & 0.241 \\
\hline Women & $57.440 \pm 14.940(34-84)[49.500-72.250](n=16)$ & $68.140 \pm 10.110(52-85)[60-78](n=14)$ & 0.032 \\
\hline Men and women & $62.460 \pm 12.310(31-88)[54-72]$ & $62.670 \pm 11.720(39-85)[54-72]$ & 0.919 \\
\hline \multicolumn{4}{|l|}{ Clinical parameters } \\
\hline Weight (kg) & $86.440 \pm 18.160$ (43.900-140.000) [76.350-98.230] & $85.800 \pm 20.350(51.000-140.000)$ [71.000-99.000] & 0.846 \\
\hline \multicolumn{4}{|l|}{ Blood pressure $(\mathrm{mm} \mathrm{Hg})$} \\
\hline Systolic & $125.690 \pm 15.730(85-170)$ [115.000-138.000] & $125.660 \pm 15.150$ (95-169) [115.500-135.000] & 0.990 \\
\hline Diastolic & $75.670 \pm 11.100(50-115)$ [70.000-80.000] & $73.060 \pm 11.780$ (40-103) [63.000-80.500] & 0.185 \\
\hline Heart rate (beats/minute) & $70.860 \pm 13.880(50-110)$ [60.000-77.750] & $70.740 \pm 14.880$ (46-111) [60.000-77.500] & 0.960 \\
\hline Missing values $(n)$ & 2 & 5 & \\
\hline Primary diagnoses & & & 0.383 \\
\hline Acute coronary syndrome & 33 & 38 & \\
\hline Heart surgery & 26 & 15 & \\
\hline Heart failure & 9 & 9 & \\
\hline Artery sclerosis and heart failure & 6 & 6 & \\
\hline Civil status & & & 0.572 \\
\hline Single & 12 & 9 & \\
\hline Married or living with a partner & 58 & 57 & \\
\hline Missing & 2 & 3 & \\
\hline Education & & & 0.898 \\
\hline Elementary school & 21 & 16 & \\
\hline High school & 8 & 7 & \\
\hline Skilled worker & 26 & 26 & \\
\hline Short education & 1 & 3 & \\
\hline Bachelor's degree & 10 & 10 & \\
\hline Master's degree & 3 & 3 & \\
\hline Missing & 3 & 4 & \\
\hline Work status & & & 0.325 \\
\hline Works under $20 \mathrm{~h} /$ week & 2 & 4 & \\
\hline Works 20-36 h/week & 1 & 4 & \\
\hline Works full-time $37 \mathrm{~h} /$ week & 10 & 9 & \\
\hline Sick leave & 16 & 12 & \\
\hline Unemployed & 0 & 2 & \\
\hline Retired & 36 & 28 & \\
\hline Missing & 7 & 10 & \\
\hline
\end{tabular}




\begin{tabular}{|c|c|c|c|}
\hline Place of rehabilitation & & & 0.560 \\
\hline Hospital & 28 & 29 & \\
\hline Healthcare center & 31 & 40 & \\
\hline
\end{tabular}

Age and clinical parameters are mean \pm standard deviation values (minimum-maximum) [interquartile range]. Other values are number of patients.

\section{Table 4. Use of Resources}

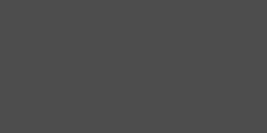

TYPE OF COSTS

Resource use (min) in Teledialog

\begin{tabular}{l|c|c|c}
\hline Staff time (information to patients) & 85 & 60 & - \\
\hline Staff time (dialogue with patients at home) & 120 & - & - \\
\hline Visit at patient's home & 45 & 45 & - \\
\hline Collecting and cleaning devices & 45 & \\
\hline Use of rehabilitation services
\end{tabular}

\begin{tabular}{|c|c|c|c|c|c|c|c|}
\hline \multicolumn{8}{|l|}{ Contacts $(n)$ with } \\
\hline Nurse & 68 & 2.480 & $(1.880 ; 3.090)$ & 66 & 2.860 & $(2.230 ; 3.500)$ & 0.380 \\
\hline Doctor & 68 & 0.710 & $(0.480 ; 0.930)$ & 66 & 0.700 & $(0.470 ; 0.920)$ & 0.984 \\
\hline Physiotherapist & 68 & 5.000 & $(2.800 ; 7.200)$ & 66 & 2.890 & $(1.230 ; 4.560)$ & 0.351 \\
\hline Dietician & 68 & 0.340 & $(0.090 ; 0.580)$ & 66 & 0.360 & $(0.120 ; 0.600)$ & 0.390 \\
\hline Psychologist & 68 & 0.180 & $(0,000 ; 0.440)$ & 66 & 0.200 & $(0.000 ; 0.560)$ & 0.976 \\
\hline Participations $(n)$ in team training & 68 & 2.220 & $(0.830 ; 3.610)$ & 66 & 3.440 & $(1.750 ; 5.130)$ & 0.251 \\
\hline \multicolumn{8}{|l|}{ Use of healthcare } \\
\hline Inpatient days ( $n$ ) & 68 & 1.020 & $(0.530 ; 1.520)$ & 66 & 0.600 & $(0.250 ; 0.950)$ & 0.429 \\
\hline Re-admissions ( $n$ ) & 68 & 0.490 & $(0.250 ; 0.600)$ & 66 & 0.350 & $(0.200 ; 0.500)$ & 0.496 \\
\hline Outpatient visits $(n)$ & 68 & 4.290 & $(2.350 ; 6.230)$ & 66 & 3.820 & $(2.190 ; 5.450)$ & 0.868 \\
\hline Length of stay (days) for each admission & 33 & 3.880 & $(2.440 ; 5.320)$ & 24 & 2.290 & $(1.200 ; 3.380)$ & \\
\hline \multicolumn{8}{|l|}{ Contacts $(n)$ with } \\
\hline GP & 68 & 15.120 & $(12.070 ; 18.160)$ & 66 & 14.670 & $(11.230 ; 18.100)$ & 0.680 \\
\hline Emergency physician & 68 & 0.720 & $(0.400 ; 1.040)$ & 66 & 1.450 & $(1.130 ; 1.780)$ & 0.980 \\
\hline Reimbursed transportation visits $(n)$ & 68 & 9.010 & $(6.160 ; 11.870)$ & 66 & 9.270 & (6.790; 11.750) & 0.301 \\
\hline
\end{tabular}

$\mathrm{Cl}$, confidence interval; GP, general practitioner. 


\section{KIDHOLM ET AL.}

\section{Table 5. Mean Cost per Patient in the Telerehabilitation and Control Groups \\ INTERVENTION GROUP \\ TYPE OF COSTS \\ \begin{tabular}{l|l|l}
$N$ & MEAN COST & $\mathrm{Cl}(95 \%)$
\end{tabular} \\ CONTROL GROUP \\ MEAN COST $\quad \mathrm{Cl}(95 \%)$

Costs of Teledialog

\begin{tabular}{l|l|c|c}
\hline \multicolumn{2}{l|}{ Time (min) } & 51 & 36 \\
\hline Staff time information to patients) & 72 & - & - \\
\hline Staff time (dialogue with patients) & 13 & - & - \\
\hline Visit at patient's home & 13 & & \\
\hline Collecting and cleaning devices & & \\
\hline
\end{tabular}

Devices' cost

\begin{tabular}{l|c|c|c}
\hline Rent of telemedicine devices (3 months) & 101 & - & - \\
\hline Rent of tablet & 32 & - & - \\
\hline Fitbit Ultra & 31 & 36 & 36 \\
\hline Activeheart.dk & 79 & 392 & \\
\hline Total running costs & & \\
\hline
\end{tabular}

Cost of rehabilitation services

\begin{tabular}{|c|c|c|c|c|c|c|c|}
\hline \multicolumn{8}{|l|}{ Contacts with } \\
\hline Nurse & 68 & 84 & $(61 ; 106)$ & 66 & 82 & $(59 ; 104)$ & 0.978 \\
\hline Doctor & 68 & 16 & $(10 ; 20)$ & 66 & 16 & $(11 ; 21)$ & 0.876 \\
\hline Physiotherapist & 68 & 199 & $(116 ; 281)$ & 66 & 92 & $(9 ; 176)$ & 0.145 \\
\hline Dietician & 68 & 9 & $(2 ; 15)$ & 66 & 10 & $(4 ; 17)$ & 0.456 \\
\hline Psychologist & 68 & 12 & $(0 ; 32)$ & 66 & 10 & $(0 ; 30)$ & 0.989 \\
\hline Participations in team training & 68 & 7 & $(3 ; 10$ & 66 & 20 & $(16 ; 23)$ & 0.190 \\
\hline Total cost of rehabilitation & & 326 & $(232 ; 419)$ & & 229 & $(160 ; 299)$ & 0.570 \\
\hline \multicolumn{8}{|l|}{ Costs of healthcare services } \\
\hline Admissions & 68 & 4,224 & $(1,519 ; 6,927)$ & 66 & 3,002 & $(986 ; 5,019)$ & 0.507 \\
\hline Outpatient visits & 68 & 533 & $(290 ; 775)$ & 66 & 519 & $(291 ; 748$ & 0.815 \\
\hline \multicolumn{8}{|l|}{ Contacts with } \\
\hline GP & 68 & 179 & $(139 ; 218)$ & 66 & 166 & $(127 ; 205)$ & 0.598 \\
\hline Emergency physician & 68 & 12 & $(6 ; 18)$ & 66 & 24 & $(9 ; 38)$ & 0.913 \\
\hline Transportation costs & 68 & 43 & $(22 ; 65)$ & 66 & 68 & $(46 ; 91)$ & 0.038 \\
\hline Total costs of healthcare utilization & & 4,991 & $(2,286 ; 7,695)$ & & 3,780 & $(1,679 ; 5,879)$ & 0.936 \\
\hline Total costs & & 5,709 & $(2,990 ; 8,427)$ & & 4,045 & $(1,917 ; 6,173)$ & 0.0211 \\
\hline
\end{tabular}

All costs are given in euros.

$\mathrm{Cl}$, confidence interval; GP, general practitioner. 


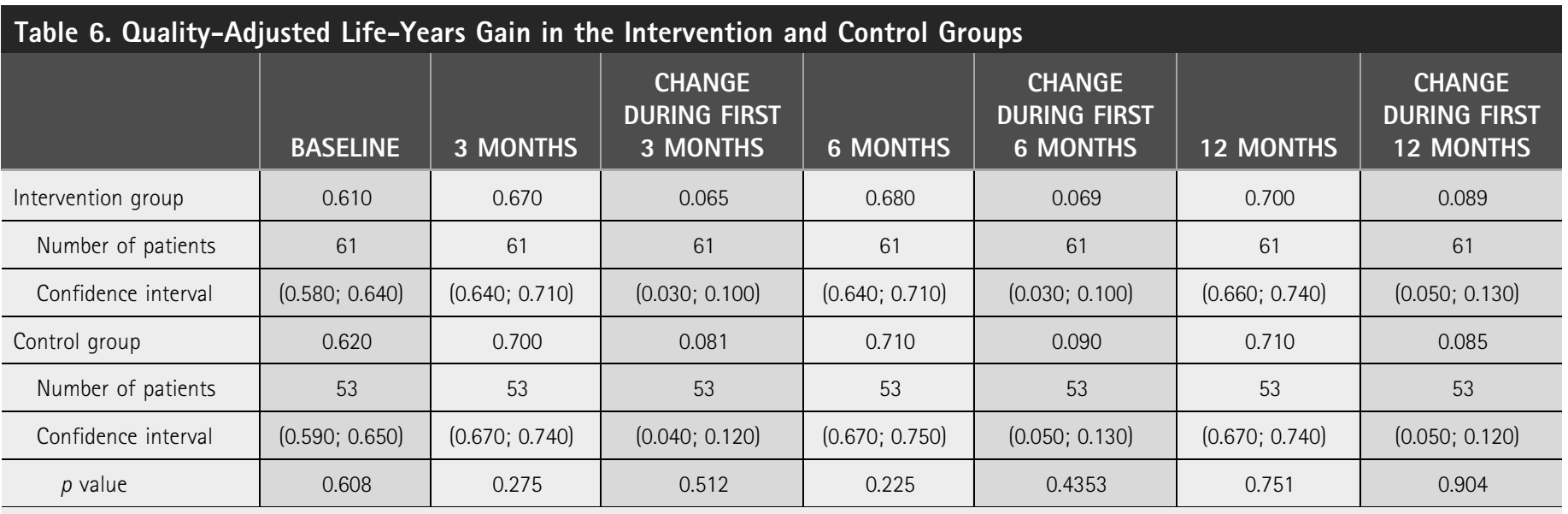

reduced the difference in the mean costs per patient to $€ 1,011$. Second, fixed costs related to the investment in telemedicine devices were excluded (costs of rent of telemedicine devices, rent of the tablet computer, purchase of the Fitbit [San Francisco, CA] Ultra tracker, and establishing of the Activeheart.dk Web site) in order to estimate the marginal costs of offering the intervention to additional patients. This reduced the difference in the mean cost per patient to $€ 1,423$. Finally, the mean cost per patient was estimated, excluding the 15 patients for whom 12 months of follow-up data do not exist. This reduced the difference in the mean costs per patient to $€ 1,023$.

\section{Discussion}

The aim of the project was to develop and test an individualized CTR program to increase participation in rehabilitation, improve patient quality of life, reduce the number of admissions, and reduce use of acute care. The CUA shows that the intervention group contacted the physiotherapist

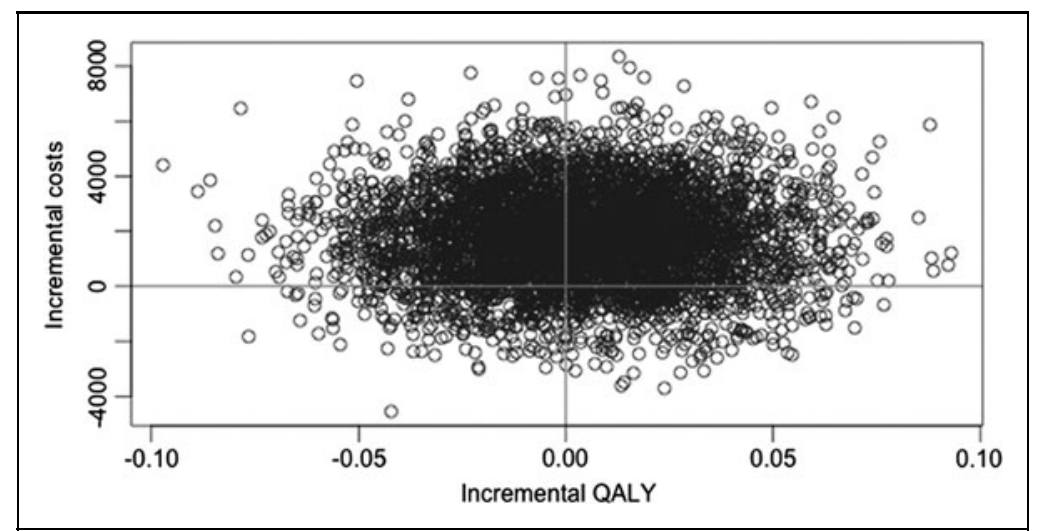

Fig. 2. Cost-effectiveness plan of incremental cost per quality-adjusted lifeyear (QALY) (bootstrapping with 5000 replications). more often while attending fewer group-training sessions compared with the control group, although these differences are not statistically significant. This suggests that patients in the telerehabilitation group are more likely to carry out their rehabilitation activities on an individual basis, thus supporting the main aim of the Teledialog project. Qualitative findings support that patients and healthcare professionals felt that the CTR program in Teledialog was tailored to individual needs. ${ }^{12}$

When examining the use of healthcare in general, the number of emergency contacts to the physician by members of the intervention group is half that of the control group, whereas the numbers of re-admissions, outpatient visits, and general practitioner visits on average are higher in the intervention group, although none of these differences is statistically significant. When comparing the overall average costs across the two groups, we find that the average cost per patient is significantly higher for those in the intervention group, except for the cost for transport, which is lower in the intervention group than in the control group.

We found no significant differences in the improvement of the patients' quality of life between the two groups $(\Delta=0.004)$, and, taken together, these results indicate that the intervention is not costeffective, with costs per QALY gained at more than $€ 500,000$. However, it is possible that the added costs of telerehabilitation may result in other desirable outcomes that were not considered in the current study. The number of cardiac patients not participating in rehabilitation is large, and these patients could benefit from a telerehabilitation approach, although at a greater cost, which may prove to be a better outcome than nonparticipation. Widmer et al. ${ }^{13}$ concluded, in a 


\section{KIDHOLM ET AL.}

systematic review and meta-analysis of digital health interventions for the prevention of CVD, that digital health interventions can reduce CVD outcomes and have a positive impact on risk factors for CVD.

In addition, the continuous collection of clinically relevant data carried out using the telerehabilitation approach may provide better support to the physician in offering improved treatment recommendations, as such clinical judgments would be based on ongoing measurements compared with the more static measures obtained from one-off, face-to-face consultations.

The strengths of this study are the wide healthcare perspective, including both primary and secondary care costs. We have not identified any study where costs from the primary and secondary sectors have been included at the same time. In addition, this study has used mainly data from patient registers rather than self-reported patient data and has had a follow-up period of 1 year.

We have identified only three other CU studies of a telerehabilitation program for patients with CVD. Körtke et al. ${ }^{14}$ presented a cost-effectiveness analysis of a nonrandomized trial of a transtelephonic guide for ambulatory rehabilitation in cardiac surgery patients. Their study showed that the total cost of the telemedicine program was lower than the conventional inhospital program. Kraal et al. ${ }^{15}$ described a protocol for a forthcoming study of a 12-week telemonitoring-guided home-based training program. Frederix et al. ${ }^{16}$ conducted a CUA of a 24 -week comprehensive CTR program using a sample of 140 patients. The study showed that the mean cost per patient in the telemonitoring program was $€ 564$ lower than the mean costs in the control group. At the same time, the mean QALY gain per patient in the telemonitoring group was 0.026 , and the conclusion therefore was that CTR tends to be more effective and efficient than centerbased CR alone. The main reason for the result was a statistically significant reduction in the number of days lost due to cardiovascular rehospitalizations in the intervention group.

The Teledialog study has several limitations. First, the project was a small-scale research project. Only healthcare costs were included in the estimation, and potential savings for the patient (e.g., savings due to a lower degree of use of pharmaceuticals) and for the municipality related to the possible improvement in the patients' quality of life were not taken into account. Using a higher number of patients may thus result in reduced costs of the devices used in the intervention and make the CTR program more cost-effective over the long term.

Second, we found an unexpected difference in the costs of outpatient and inpatient visits. Only hospital visits related to heart disease are included in the study, and based on the estimated low impact on the patients' quality of life, no difference in these costs was to be expected. Therefore, only a few patients with high healthcare costs unrelated to the degree of rehabilitation may have had a large impact on the costs. As a consequence, larger studies are needed to provide further examination of the differences in costs per patient.

Third, the measure of the patients' quality of life, the Brazier algorithm, and the SF-6D methodology may be criticized for being too generic and not sensitive enough for identifying the changes in the patient's health related to rehabilitation.

\section{Conclusions}

The current study shows that an individualized CTR program may increase the patient's participation in rehabilitation activities, reduce the cost of transport, and reduce the number of emergency physician visits. However, the mean total healthcare cost per patient in the intervention group was significantly higher, and improvement in the patients' quality of life was not significant, compared with the costs and quality of life of the patients in the control group. Taken together, these findings indicate that the telerehabilitation approach is not costeffective in a small-scale study. It is possible that increasing the number of patients in the sample may show reduced costs of the devices and make the telerehabilitation program more costeffective. In addition, increasing rehabilitation participation and perhaps the kind of clinically relevant data collected may give the telerehabilitation approach an additional advantage. More research is needed to identify the potential for the use of telerehabilitation for cardiac patients.

\section{Acknowledgments}

We wish to thank the patients and clinical partners who participated in the project (see www.teledialog.eu). The research was funded by Eir Research and Business Park, The European Regional Development Fund, UNIK Partnership, Danish Council of Research and Innovation, and partners in the project.

\section{Disclosure Statement}

No competing financial interest exists.

\section{REFERENCES}

1. Economist Intelligence Unit. The heart of the matter: Rethinking prevention of cardiovascular disease. Available at www.economistinsights.com/healthcare/ analysis/heartmatter (last accessed July 5, 2015).

2. Jolliffe JA, Rees $K$, Taylor RS, et al. Exercise-based rehabilitation for coronary heart diseases. Cochrane Database Syst Rev 2001 ;(1):CD001800.

3. Heran BS, Chen JM, Ebrahim S, et al. Exercise-based rehabilitation for coronary heart disease. Cochrane Database Syst Rev 2011 ;(7):CD001800.

4. Bjarnason-Wehrens B. Results from the European Cardiac Rehablitation Intventory Survey (ECRIS). European Association for Cardiovascular Prevention and Rehabilitation 2008. Eur J Cardiovasc Prev Rehabil 2010;17:410-418.

5. Meyer J. Meeting the challenges facing low cardic rehabilitation referral and participation rates. Circulation 2012;125:1321-1329. 


\section{COST-UTILITY ANALYSIS OF CARDIAC TELEREHABILITATION}

6. Frederix I, Vanhees L, Dendale $P$, Goetschalkx K. A review of telerehabilitation for cardiac patients. J Telemed Telecare 2015;21:45-53.

7. Piotrowicz E, Piotrowicz R. Cardiac telerehabilitation: Current situation and future challenges. Eur J Prev Cardiol 2013;20(2 Suppl):12-16.

8. Brazier J, Roberts J, Deverill M. The estimation of a preference based measrue of health from the SF-36. J Health Econ 2002;21:271-292.

9. Kharroubi SA, Brazier JE, Roberts J, O'Hagan A. Modelling SF-6D health state preference data using a nonparametric Bayesian method. J Health Econ 2007;26:597-612.

10. Drummond MJS, Torrance G, O'Brien B, Stoddart G. Methods for the economic evaluation of health care programs, 3rd ed. Oxford, United Kingdom: Oxford Medical Publications, 2005.

11. Nationalbanken [National Bank of Denmark]. Available at www.national banken.dk/da/statistik/valutakurs/Sider/Default.aspx (last accessed July 1, 2015).

12. Dinesen, B, Spindler $\mathrm{H}$. Individualized telerehabilitation for heart patients across municipalities, hospitals and medical disciplines: Preliminary findings from the Teledialog project. Int J Integr Care 2014;14(International Digital Health and Care Supplement). URN:NBN:NL:UI:10-1-116515.

13. Widmer RJ, Collins NM, Collins CS, West CP, Lerman LO, Lerman A. Digital health interventions for the prevention of cardiovascular disease: A systematic review and meta-analysis. Mayo Clin Proc 2015;90:469-480.

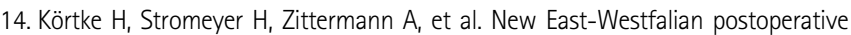
therapy concept: A telemedicine guide for the study of ambulatory rehabilitation of patients after cardiac surgery. Telemed J E Health 2006;12:475-483.

15. Kraal JJ, Peek N, Akker-Van marle ME, Kemps HMC. Effects and costs of homebased training with telemonitoring guidance in low to moderate risk patients entering cardiac rehabilitation: The FIT@Home study. BMC Cardiovasc Disord 2013;13:82.

16. Frederix I, Hansen D, Coninx $K$, Vandervoort P, Vandijck D, Hens N, Van Craenenbroeck E, Van Driessche N, Dendale P. Effect of comprehensive cardiac telerehabilitation on one-year cardiovascular rehospitalization rate, medical costs and quality of life: A cost-effectiveness analysis. Eur J Prev Cardiol 2015 August 19 [Epub ahead of print]. pii: 2047487315602257. doi: 10.1177| 2047487315602257.

Address correspondence to: Birthe Dinesen, PhD Telehealth and Telerehabilitation Laboratory of Assistive Technologies SMI

Department of Health Science and Technology Faculty of Medicine Aalborg University Aalborg, 9000 Denmark

E-mail: bid@hst.aau.dk

Received: October 4, 2015 Accepted: November 12, 2015 